\title{
A framework for evaluating management plans comprehensively
}

\author{
Verena M Trenkel ${ }^{1, *}$, Marie-Joëlle Rochet ${ }^{1}$ and Jake C Rice ${ }^{2}$ \\ ${ }^{1}$ IFREMER, Nantes Cedex 03, France \\ ${ }^{2}$ Department of Fisheries and Oceans, National Advisor - Ecosystem Sciences, Ottawa, Ontario, Canada \\ *: Corresponding author: Verena M Trenkel, tel.: +33 240374000 ; fax: +33240374075 ; \\ email address : vtrenkel@ifremer.fr
}

\begin{abstract}
:
We present a framework for evaluating fisheries management plans comprehensively, both rebuilding plans and others. The framework includes a first rapid appraisal of the likelihood that the plan will result in management meeting its objectives, and guides subsequent quantitative analyses of potential weaknesses in the proposed plan. The framework includes four steps: (i) evaluating if a set of management objectives, if achieved, would result in a sustainable fishery, (ii) using qualitative analysis of a bio-economic model to evaluate whether the set of stock management tactics might be capable of achieving the specified fisheries objectives, (iii) using empirical criteria derived from the literature to evaluate if other management measures in the plan related to the ecological, social or economic context of the fishery actually contribute to sustainability, and (iv) carrying out quantitative simulations to compare alternative implementation options. Generally, several management measures have to be combined to increase stock size without sacrificing the economic benefits to the fishers remaining in the fishery. We demonstrate application of the framework for evaluating the stock rebuilding plan for plaice (Pleuronectes platessa) and sole (Solea solea) in the North Sea and, the management measures currently in place for the roundnose grenadier (Coryphaenoides rupestris) stock exploited to the west of the British Isles.
\end{abstract}

Keywords: Loop analysis ; management strategy ; management strategy evaluation ; qualitative modelling ; stock rebuilding ; sustainability 


\section{Table of content}

\section{Introduction}

\section{The framework}

2.1 Assessing the sustainability of management objectives (step 1)

2.2 Assessing the potential outcome of management measures (step 2)

\subsubsection{Approach}

2.2.2 Bio-economic fishery model

2.2.3 Alternative bio-economic model formulations

2.2.4 Evaluating management measures

2.3 Assessing complementary socio-economic, ecosystem and monitoring management measures (step 3)

2.4 Quantitative simulations (step 4)

\section{Applications}

3.1 Plaice and sole

3.1.1 Background information

3.1.2 Applying the evaluation framework

3.1.3 Insights from applying the evaluation framework

3.2 Roundnose grenadier

3.2.1 Background information

3.2.2 Applying the evaluation framework

3.2.3 Insights from applying the evaluation framework

\section{Discussion}

\section{Acknowledgements}

\section{References}




\section{Introduction}

Multi-annual fisheries management plans are being developed worldwide as fisheries management organizations strive for sustainability. Many jurisdictions have concluded that the objective of sustainable exploitation will be more effectively achieved through a multiannual approach, involving multi-annual management and recovery plans, instead of annual approaches. According to the European Union (2002) multi-annual management plans "should establish targets for sustainable exploitation of the stocks concerned, contain harvesting rules laying down the manner in which annual catch and/or fishing effort limits are to be calculated and provide for other specific management measures, taking account also of the effect on other species." In this policy guidance the selected management measures are catch and effort limits for which harvest control rules are set. Similar trends to multi-year management are occurring in Canada (http://www.dfo-mpo.gc.ca/fm-gp/sdc-cps/multi-yearpluriannuels-eng.htm, accessed 26 July 2013), the US (http://www.gpo.gov/fdsys/pkg/FR2013-03-07/html/2013-05330.htm, accessed 26 July 2013) and many other jurisdictions. In these multi-year plans, a wide range of additional management measures may be used, including gear restrictions, minimum landing size, restricted fishing seasons and areas in addition to effort and catch limits (Hilborn and Walters, 1992). What we call here a management plan has at least three components: 1) stock related objectives; 2) management measures and corresponding harvesting rules to achieve the objectives; 3 ) other fishery management measures designed to enhance the success of the management measures by improving the socio-economic and ecological context.

We use the following definitions in the remainder of this manuscript. Management tactics combine management measures for a set of the variables, such as catches, effort, gear type, landing size, etc. (Hilborn and Walters, 1992). In this paper we restrict management tactics to target stocks. A harvest (control) rule, also called a decision rule (Butterworth et al., 1997), is a rule or formula for calculating the amounts of these variables that can be taken or deployed by the fishery. These are decided upon periodically, generally based on updated information. We use the term ,other fishery management measures" for measures concerned with the wider ecosystem, in particular non-target species and the habitat, and the socio-system, e.g. accompanying socio-economic measures.

The performance of a management plan is the extent to which it delivers its objectives which can only be evaluated retrospectively. But before launching a management plan, managers need to evaluate and compare the ability of various possible tactics, and other management measures, to result in the stock and fishery meeting the sustainability objectives. The expected performance of management plans is commonly evaluated beforehand by model simulation (Management Strategy Evaluation - MSE). MSE describes the ecological dynamics and ideally also the economic and social dynamics of the fishery, and the management loop from data acquisition and stock assessment through decision making, to implementation of the management and performance of the fishery, see Bastardie et al. (2010) for a cod example. The intention of MSE is to evaluate as comprehensively as possible the likelihood of success of a given management plan, while accounting for uncertainty and complexity of interactions (Punt and Donovan, 2007, Bence et al., 2008, Sainsbury et al., 2000); comparing alternative control options is often part of the investigations. A complementary view is that if a management plan does not perform adequately in simulations there is little chance it will do so in practice (Sainsbury et al., 2000).

Carrying out comprehensive quantitative simulations is costly and technically demanding, and more fundamentally there is poor or incomplete knowledge of many of the underlying processes that these models simulate, and of their parameters, which poses a number of operational problems (Rochet and Rice, 2009). Regardless of the richness of the information 
available to support the model formulations, for quantitative simulations functional relationships must be specified for ecological, economic, behavioural, and social/governance processes; many of which are likely to be stochastic and often poorly documented. Quantitative MSE can attempt to take account of poorly known or undocumented processes by including multiple alternative formulations of such processes. However, if the results of models with different formulations of a specific process are to be combined, weights need to be assigned to these multiple formulations, requiring additional quantification of the relative likelihood of each formulation or qualitative ranks.

In addition, for each formulation of each process the joint statistical distributions of the parameters of the suite of functional relationships must be defined whether by estimation from relevant data sets or by "expert judgement" [i.e. "guessing"] when they are not well documented. This makes using multiple formulations of uncertain processes even more challenging to implement, because to the extent that the formulations are different enough to warrant consideration, the joint statistical distributions of the suites of functional relationships are also likely to differ. Although quantitative MSE tries to use the best information available, inevitably such approaches multiply the technical demands of the quantitative MSE process, increase the uncertainty of results, and limit their intelligibility and possibly even their usability.

Notwithstanding the consensus among fisheries science advisors and managers that it is important to take account of uncertainty when making any management decisions, the above considerations underscore the complexity of fully exploring uncertainty of all management options before choosing which one to implement. Instead of trying to build comprehensive models and scan the complete suite of formulations and parameter ranges that are plausible given the available knowledge, an alternative approach to tackle uncertainty is a two stage approach, where the first stage is qualitative and the second stage quantitative. In the first stage, minimalist general models are built. Uncertainty is addressed by making as few assumptions as possible - that is, examining model structure rather than specified formulations and parameterizations. Since the models are not fully quantified, they cannot be used to make quantitative comparisons, but still, analysis of some of their qualitative properties can provide knowledge useful to management - for example, monotonicity properties, limit behaviour, or how an increase in one variable affects another variable. Uncertainty is further addressed by using several alternative model structures that are plausible, given the available knowledge. This has some similarity to using multiple formulations of uncertain processes in an MSE, but carries neither the burden of specifying the joint multiple parameter distributions nor the need to weight outputs of various formulations. Rather, the qualitative results that are robust across these structures are those of greatest interest. Let us note that this approach is completely deterministic - there is no attempt to quantify parameter distributions or event probabilities, nor to calculate model likelihood. Those factors can be quantified at the second stage where quantitative simulations for subsets of the system are used to compare different implementation options, e.g. two types of harvest rules.

A qualitative approach (stage 1) is able to rapidly screen the three components of a management plan for their chances of failure. Plans may be screened out as likely to fail because the include either (i) objectives that are not compatible with sustainable exploitation, or (ii) tactics and other measures that cannot be expected to get the stock and fishery to meet the sustainability objectives. Thus, for evaluating the failure of management tactics and measures, the idea is to obtain general results which are robust across alternative, reasonable model structures without specifying model formulations and their parameterisations. From this smaller set of candidate objectives and management tactics, more quantitative evaluations of the likelihood of various outcomes and their possible 
trajectories (e.g. transition costs, time courses for outcomes, etc) can be explored efficiently, if desired or required by legislation, by quantitative simulations (stage 2).

Here we propose an evaluation framework that uses as much as possible of what we do know, and makes as few assumptions as possible regarding things about which we actually know little. Our approach has four steps, with steps 1 to 3 relating to the qualitative stage 1 described above (Table 1). The first step is to evaluate whether the objectives of the management plan are consistent with sustainable exploitation. In the second step, the adequacy of the planned management tactic or combination of tactics for achieving the objectives are evaluated qualitatively. For this second step, the structure of a bio-economic model is first formulated and then used to evaluate the proposed management tactics using qualitative modelling. In the third step, the complementary socio-economic, ecosystem and monitoring measures included in the management plan are evaluated regarding their contribution to the overall success of the plan. This latter evaluation uses expert-derived criteria from retrospective empirical evaluations of management plans found in the scientific literature. In the fourth step, quantitative simulations are carried out for specific implementation issues. In summary, the outcome of applying the evaluation framework is an assessment of i) the sustainability of the objectives of the management plan, ii) the qualitative outcome of the selected tactics (i.e. likely to fail or possibly could succeed) predicted from the structural analysis of the bio-economic system, iii) the expected overall outcome of the plan based on past performance of the complementary measures in the plan, and iv) quantitative results for specific issues. The objective of the first three steps is to systematically screen out management plans that have little chance of success before resorting to time consuming quantitative simulations in step 4.

The proposed approach can be used to evaluate any management plan, including rebuilding plans, multi-annual fishing plans, and other plans. However, the qualitative modelling proposed for evaluating management tactics in the second step only applies to situations that aim at bringing a fishery to a different state or keeping a fishery sustainable if conditions associated with the fishery change. The qualitative modelling provides little insight into status quo management that just aims at keeping a stock or fishery in a state already in place.

In the next section we present methods that can be used for carrying out each evaluation step. We then use the evaluation framework for two case studies. Sole and plaice in the North Sea are currently managed within a common, formally agreed recovery plan. Roundnose grenadier has no formal legally agreed plan but all ingredients for a management plan exist.

\section{The framework}

\subsection{Assessing the sustainability of management objectives (step 1)}

In this section we describe how to assess whether the objectives of the management plan are consistent with sustainable exploitation. This assessment is based on the elements described in the management plan in combination with stock information (Table 1).

Quinn and Collie (2005) pointed out that "sustainable" means different things to different persons - essentially it implies the ability to last long. To make it operational for single stock management, they defined four sustainability categories based on a review of the development of the concept of sustainability in fisheries science and identification of historic periods: 
- The classical view was deterministic and the primary tool for achieving sustainability was the control of fishing mortality $F ; F_{\text {msy }}$ was a target, and a higher F-value such as $F_{\text {ext }}$ (fishing mortality driving the population to extinction) was used as a limit.

- The neo-classical view acknowledged depensation and stochasticity, and thus considered both $\mathrm{F}$ - and stock biomass B-based reference points. $F_{\text {msy }}$ was still considered a target but F-limits were lower than in the classical view, with the new limits $F_{\text {thresh }}$ corresponding to fishing mortalities driving the populations below the biomass limits $B_{\text {thresh. }}$

- In the modern view the primary objective was to preserve spawning stock biomass SSB. Harvest control rules were defined, including more precautionary limit reference points (higher $B$, lower $F$ ); in that view $F_{m s y}$ was used as a limit and $B$ targets were unlikely to be lower than $B_{\text {msy. }}$.

- The post-modern view is more ecosystem-based and takes account of the economic and social dimensions of a fishery more explicitly, as well as being at least as precautionary as the modern view with regard to $\mathrm{F}$ and $\mathrm{B}$ of the target species.

The post-modern view is still under development and no single preferred set of objectives has emerged. There is growing awareness that multiple objectives might have to be traded off, however (Link, 2010). Thus, strategies that consider something in addition to SSB and F in their goals can be classified as post-modern. Where targets and limits for SSB and $F$ of target species are in the set of ecological objectives, they are unlikely to be less stringent than in the modern view. For example, Australia adopted $B_{\text {mey }}$ as target biomass level (Department of Agriculture, 2007) and it is well known that $B_{\text {mey }}$ is generally lower than $B_{m s y}$, though not necessarily by much (Christensen, 2010).

Practically, management reference points for both mature biomass (SSB) and fishing mortality $(F)$ are usually available for a stock with a full analytical assessment. The reference points ideally include both targets for SSB and F, reflecting desired social and economic outcomes of exploitation of a healthy stock, and limits, reflecting a situation where risk of serious harm to stock productivity (SSB limits) or consistent decline towards such a state (F limits) begins to increase markedly (Caddy and Mahon, 1995). If the limit reference points are estimated properly, then a fishery will be ecologically sustainable as long as management keeps the mature biomass at a low likelihood of being less than the biomass limit, and the fishing mortality at a low likelihood of exceeding the fishing mortality limit. If the target reference points are positioned correctly relative to the limits, and are the product of governance processes that did capture social and economic goals effectively, then managing to keep mature biomass and fishing mortality near their respective targets will achieve ecological, social and economic sustainability, if such full sustainability is possible to achieve.

Thus, for stocks with full analytical assessments management plans can be categorised in terms of the type of sustainability they strive for. Ways for evaluating the sustainability of objectives in the case of data limited fisheries with no full analytical assessment or for the wider ecosystem will be considered in the discussion. 


\subsection{Assessing the potential outcome of management measures (step 2)}

\subsubsection{Approach}

There are many ways for analyzing qualitative properties of partly specified models, such as the expected directions of change of state variables in response to changes (perturbations) to other linked state variables. Here we use press perturbation analysis of signed digraphs models that just specify a list of dynamic state variables and the signs of their interactions; for fisheries examples see Dambacher et al. (2009). Mathematically the models consist in systems of ordinary differential equations that are not functionally specified - they are just supposed to be monotonous. To carry out a press perturbation analysis the model system needs to have at least one equilibrium state, in the vicinity of which the equations can be linearised. This amounts to the simple assumption that the model system processes are continuous in the neighbourhood of the current equilibrium status. The principle of qualitative model analysis, also called loop analysis, is to consider the expected directions of change from the current to the next equilibrium when a permanent change occurs in one or several of the model state variables (Puccia and Levins, 1985). These expected changes are the combined results of direct effects and indirect effects created by feedback loops when perturbations propagate through the links between state variables.

Many management tactics can be translated into a permanent change in one or several of the state variables which means the consequences management tactics can be formally predicted by a single or multiple press perturbation analysis (Puccia and Levins, 1985, Nakajima, 1992, Dambacher et al., 2002). There is little basis to assume that fishery systems are ever at equilibrium - they are continuously moving as various drivers fluctuate (Kraak et al., 2012). However, we are looking at the response of the system in the neighbourhood or current status, even if the status is far from a long-term equilibrium condition. Local linearization in modelling is a long established practice (Ellner and Gross, 1982, Dwyer and K.T., 1983). It is not without its risks, but suitable for qualitative analysis where the answer being sought is whether it is at least possible that the system will move in the direction of greater sustainability. If the structural analysis in step 3 concludes a management tactic will fail even in a locally linearized system it is not considered plausible it would be found to be likely to succeed in more complex formulations of the local neighbourhood. Below we propose a list of models that can be used for the purpose of evaluating management strategies qualitatively, and present the results of press perturbation analyses for these models.

\subsubsection{Bio-economic fishery model}

Rochet et al. (2012) proposed a simple bio-economic model for evaluating joint stock-fleet dynamics in the Bay of Biscay, referred to below as the core model (Figure 1).

The model describes the network of direct links between system variables in an unregulated fishery. The system variables considered in the model are fishing capacity, fishing effort, stock dynamics, catches, net earnings and profitability. In the model fishing capacity $K$ describes capital invested in vessels and fishing gears. Thus fishing capacity could be measured by total engine power of the fleet or other indicators. Economic fishery performance is encapsulated in the return on capital invested (Profitability $P$ ). Profitability is decreased by fixed costs which depend on fishing capacity and increased by net earnings. Net earnings $R$ are total earnings (Landings $\times$ Prices) minus variable fishing costs. Stock $S$ represents stock abundance, either total number or biomass or spawning stock biomass.

Several model variables are linked to management measures (Figure 1). Quota changes will regulate catches $C$, various measures of input control will modify effort $E$ or/and fishing 
capacity $K$ while fiscal measures such tax exemption of fuel, can influence costs and thus net earnings $R$ or profitability $P$. In the model context, implementing any such measure in a tactic amounts to influencing the level of the concerned variables externally.

The core model has one positive feedback loop E-C-R-P-K-E (effort - catch - net earnings profitability - capacity - effort), which would tend to destabilise the system. But this is counteracted by three negative links from effort to net earnings $(E-R)$, from capacity to profitability $(K-P)$ and from effort to stock $(E-S)$.

\subsubsection{Alternative bio-economic model formulations}

For the bio-economic model to provide relevant predictions, it needs to offer an adequate description of the stock and fishery under investigation. To illustrate how the core model can be adapted to particular situations, we define four model variants by removing certain links from the core model. In some situations knowledge may not be sufficient to decide which model structure is the most adequate. In that case several model structures can be investigated.

In model 1 (external income), there is no link from revenue to profitability $(R-P)$ : this can happen if there are subsidies for fixed costs, or sources of income independent of fishing. In that case no closed feedback loop links all model variables together. Thus model variables are relatively independent and perturbations on one variable will have limited effects on other variables.

In model 2 (variable cost subsidies), the link from effort to revenue $(E-R)$ does not exist, which can happen when variable fishing costs are subsidised, e.g. fuel subsidies. Removing this link cuts the stabilising (negative) economic feedback loop $P-K-E-R-P$.

In model 3 (subsidies \& overcapacity), there is no direct link from effort to revenue (as in model 2) and in addition no link from effort to catch (E-C). The latter describes a situation with fishing overcapacity in which catches are only a function of stock abundance, i.e. there is a saturation with respect to effort (adding or removing effort does not change total catches). This leaves one single long stabilising (negative) feedback loop in model 3 , and to some extent re-establishes the balance between effort and revenue which was suppressed in model 2.

In model 4 (capacity cap), the investment of profits into capacity increases is prohibited $(P-K$ link removed). This occurs in situations with fishing licences and vessel power caps and prohibition of other technical improvements which would increase fishing capacity. Cutting this link removes the long positive destabilizing feedback loop (E-C-R-P-K-E), thus increases model stability.

Other model formulations can be obtained by adding or removing variables and/or links. Certain management measures might affect model structure; others may change permanently the level of a state variable. For example, bycatch and discards may be included as additional variables to analyse the effects of bycatch reduction measures. Spatial closures are an example where the core model might still be appropriate if they result in reduced availability, which might be considered equivalent to reduced catches, or if they increase stock size by enhancing recruitment. Certification schemes often result in increasing fish price, so strengthen the link from catch to net earnings, but do not directly modify any link or variables. Other management measures can be introduced, simply by reasoning out which state variables or strength of linkages in the model will be altered and in which direction, but does not require quantification of the magnitude of the changes. The bio- 
economic model only includes a single species and thus ignores technical and biological interactions. Models of greater complexity can be explored - e.g., (Rochet et al., 2013).

\subsubsection{Evaluating management measures}

For those management tactics that can be represented by a permanent change in the level of one or several model variables (nodes in Figure 1), but not the removal of variables or linkages, we used qualitative analysis to predict the directions of change in model variables following the implementation of the tactic. For the core model the following equations apply:

$$
\begin{gathered}
\frac{d S}{S d t}=-a_{s s} f_{s}(S)+\theta_{s} / S-a_{s e} E \\
\frac{d C}{C d t}=-a_{c c} f_{c}(C)+\theta_{c} / C+a_{c s} S+a_{c e} E \\
\frac{d R}{R d t}=-a_{r r} f_{r}(R)+\theta_{r} / R+a_{r c} C-a_{r e} E \\
\frac{d P}{P d t}=-a_{p p} f_{p}(P)+\theta_{p} / P+a_{p r} R-a_{p k} K \\
\frac{d K}{K d t}=-a_{k k} f_{k}(K)+\theta_{k} / K+a_{k p} P \\
\frac{d E}{E d t}=-a_{e e} f_{e}(E)+\theta_{e} / E+a_{e k} K
\end{gathered}
$$

where $f_{x}(\mathrm{X})$ is a positive function of variable $X$ describing self-effects, $\theta_{x}$ is a constant percapita birth rate (for ecological variables) or renewal rate (for economic variables), and the $a_{y x}$ coefficient describes the direct link between variable $X$ and $Y$. Self-effects are links that connect a variable to itself and represent either self-limiting or self-enhancing growth, or the relation of the variable to an outside resource or process not specified in the model (Puccia and Levins, 1985); for a stock with a negative self-effect it corresponds to logistic growth.

Concretely, we use qualitative model analysis to evaluate whether the proposed management tactic is likely to achieve the objectives stated in the plan. For illustration we take the case of a rebuilding plan but any management plan can be evaluated, as long as it includes changing permanently one or several of the state variables. A central objective of all stock rebuilding plans is to permanently increase stock size $S$ to which we choose to add the economic objective that this should be achieved without decreasing both profitability $P$ and net earnings $R$. The rationale for this is that a measure that will decrease these economic variables will be opposed by fishers, who will pressure against the establishment and enforcement of the management plan, and/or not comply with it.

For the hypothetical rebuilding plan and all model variants we qualitatively evaluated the expected effects of different management tactics: a decrease in quota (decrease in $C$ ), effort limitation (decrease in $E$ ), an increase in taxes (decrease in $R$ ) or capacity limitation (decrease in $K$ ), either separately or in combination. The results are presented as the direction of change of each model variable following implementation of the management tactic, i.e. increase, decrease or no change of the modelled state variable (Table 2). Ambiguous predictions caused by counteracting effects are given in brackets. Uncertain results (noted by a question mark in table 2) occur when there are as many positive as negative feedbacks acting on a given state variable. Differing results for the four model variants are indicated in table 2 and presented in full as Supplementary Material (table S1).

For the core model, quota-only strategies, and any strategy involving decreasing economic variables (increased taxes or decreased subsidies leading to decreased net earnings $R$ ) are prone to failure owing to their expected long term detrimental effect on the economic variables net earnings and profitability; short term decreases in economic variables are not 
evaluated with this modelling approach but often occur for a range of management tactics during the initial transition period. In contrast, under certain circumstances a decrease in effort $E$ or capacity $K$, alone or combined, or a combination of quota reduction $C$ and effort reduction is more likely to be accepted for their predicted possibly positive or neutral effect on the economic variables $R$ and $P$. The conditions for ambiguous predictions can be examined algebraically (see also Dambacher et al. (2009)).

For ambiguous predictions of the core model (results in brackets in Table 2) related to a decrease in effort $E$, conditions for resolving the ambiguities amount to the sign of the quantity $A=a_{s s} a_{c c} a_{r e}-a_{s s} a_{r c} a_{c e}+a_{c s} a_{r c} a_{s e}$. If $A$ is positive, $R, P$ and $K$ will increase when effort is decreased. The link $a_{r c}$ from catch to revenue occurs both in the positive and negative parts of $A$, thus will not be determining. $A$ will be higher (thus more likely positive) if any of three conditions apply: effort is expensive ( $a_{r e}$ high - condition 1), the stock responds strongly to effort reductions ( $a_{s e}$ high, which might be enhanced in depleted stocks that contract their spatial distribution - condition 2), or catch responds weakly to effort reductions ( $a_{c e}$ low, which might happen in the case of fishing overcapacity, with CPUE increasing when capacity and effort are reduced - condition 3 ). The sign of $A$ is determined by the magnitudes of these coefficients $\left(a_{\mathrm{re}}, a_{\mathrm{se}}\right.$ or $\left.a_{\mathrm{ce}}\right)$, so is beyond a qualitative analysis, but any of these three conditions or, of course, their combinations, is likely to make $A$ positive hence lead to an increase in economic variables. The same effect is achieved by decoupling net earnings and catches from effort as done in model 3 (Supplementary Material, Table S1).

There is an additional condition related to ambiguous predictions for the effect of changes in fishing capacity $K$ : if $B=a_{e k} a_{p r} A-a_{s s} a_{c c} a_{e e} a_{r r} a_{p k}<0$ then decreasing $K$ will increase profitability. This will happen if $A$ is small (or even negative) and/or if capacity (vessels and fishing gears) are expensive ( $a_{p k}$ high). The "expense" of vessels and gears has to be expense to the fishers deploying the effort; subsidies to maintain or increase employment mean that $a_{p k}$ will not be perceived as high by the fleet. Again, if a system is described by model 3 , decreasing capacity will surely lead to increased economic variables (Table S1). In contrast, assuming model 2 or model 4 makes the predictions even more uncertain (Table S1). Finally, the expression $A$ needs to be positive for a decrease in $E$ to have a positive impact on profitability, while it needs to be negative (or small) for a reduction in capacity $K$ to have a positive effect. Thus, when both effort and fishing capacity are reduced simultaneously ( $E \& K$ in table 2 ), profitability will increase in fewer instances than when only effort is reduced. Note this only holds if reducing capacity actually has some effect on effort.

We now consider deviations from the results described above for the four model variants (Table S1). In model 1 (external income), as there is no link from revenue to profitability most management tactics are not going to impact profitability but only net earnings (Table S1). In model 2 (variable cost subsidies), with no link from effort to revenue ( $a_{r e}$ absent), not decreasing economic variables is only achievable for tactics involving effort reduction but not quota or fishing capacity reduction. In model 3 (subsidies \& overcapacity), with no link from effort to revenue ( $a_{r e}$ absent), compared to the core model, the positive impacts on economic variables of a decrease in effort and/or capacity become certain. In model 4 (capacity cap), profits cannot be invested into capacity ( $a_{k p}$ absent). The results are essentially identical to the core model with the main difference that capacity $K$ is not affected by other tactics.

\subsection{Assessing complementary socio-economic, ecosystem and monitoring management measures (step 3)}

There have been several reviews and theoretical studies of a wider class of factors of success and failure of stock management plans (Murawski, 2010, Rosenberg et al., 2006, Wakeford et al., 2009, Brodziak et al., 2008). Using expert judgement we extracted five 
criteria proposed in the literature which if applied are expected to increase the success of a management plan. These criteria cover the wider socio-economic, ecosystem and monitoring aspects of fisheries.

Industry support: Equitable allocation of losses and benefits across fisheries (Brodziak et al., 2008) or homogeneity of fisheries participating during recovery, and stability of future allocations (Powers, 2003) are required for the management plan to have a chance of being adopted, implemented and complied with. If fishers bearing the impacts of reduced catch or effort for recovery of the stock do not feel they have been treated fairly, their compliance with the plan may decline and thus jeopardize its success.

Mortality reduction: It has been repeatedly observed that, for rebuilding plans, a large and rapid initial reduction in fishing mortality is key to recovery success (Rosenberg et al., 2006, Rosenberg and Morgensen, 2005, Brodziak et al., 2008, Wakeford et al., 2009).

Multi-species: To account for wider community structure, management plans must be multispecies (Rosenberg and Morgensen, 2005, Brodziak et al., 2008, Murawski, 2010), particularly for mixed fisheries that have noteworthy bycatches of the species considered in the management plan. If relevant, this could include bycatch reductions measures or spatiotemporal closures (Rosenberg and Morgensen, 2005, Murawski, 2010).

Performance indicators: Definition of unambiguous indicators for monitoring the management plan performance, and clear reference points, are required (Wakeford et al., 2009, Rosenberg et al., 2006). This includes criteria for declaring a stock rebuilt, a fishery to be reopened (Rice et al., 2003) or the objectives generally achieved (Murawski, 2010) as well as a time horizon for getting there (Powers, 2003). When setting the time horizon it is important to take into account that strongly depleted stocks are less likely to recover, and recover more slowly (Powers, 2003, Rice et al., 2003); expected recovery rates also depend on the life history of a species. If there are objectives for bycatches or discards as part of the plan, performance indicators for their achievement are needed as well (Rosenberg and Morgensen, 2005).

Monitoring program: A consistent monitoring of progress must be implemented which covers the criteria in all dimensions of the fishery and ensures that plans showing no signs of progress within the expected time horizon are revised appropriately (Rosenberg et al., 2006, Brodziak et al., 2008, Murawski, 2010).

\subsection{Quantitative simulations (step 4)}

Quantitative management strategy evaluation to support fisheries management has been carried out for other a decade. A description of the components and methods can be found in Smith et al. (1999) and Sainsbury et al. (2000). Numerous studies have used simulations for testing and comparing management strategies. We do not discuss quantitative management strategy simulation any further and refer the interested reader to the large body of published studies using this approach.

\section{Applications}

We demonstrate the application of the management evaluation framework by assessing the management plan for plaice (Pleuronectes platessa, Pleuronectidae) and sole (Solea solea, Soleidae) in the North Sea and the current management for roundnose grenadier (Coryphaenoides rupestris, Macrouridae) to the west of the British Isles. 
For applying the evaluation framework, in each case basic information about the nature of the fishery, the stock and the ecosystem as well as the assessment and management system were assembled to assess sustainability (step 1), determine the appropriate model structure before qualitatively evaluating the implemented management tactics (step 2) and evaluate the other management measures using the complementary criteria (step 3).

\subsection{Plaice and sole}

\subsubsection{Background information}

Plaice and sole have been exploited in the North Sea for centuries. Currently they are primarily caught together in a mixed beam-trawl fishery in the southern North Sea. In addition, plaice is targeted in the central part of the North Sea by a beam trawl fishery, which has been recently declining (ICES, 2012b). These fisheries are shared among all EU member states surrounding the North Sea - Sweden, Denmark, Germany, the Netherlands, Belgium, France, and the United Kingdom - and Norway. Fishing mortality of both stocks increased throughout the second half of the XXth century while landings and spawning stock biomass fluctuated with a few peaks corresponding to strong year classes (Figure 2). The mesh size used in the mixed fishery is designed to catch sole at or above its minimum landing size, which results in massive discards of undersized plaice. Since both stocks were subjected to non-precautionary levels of fishing mortality and considered at risk of being harvested unsustainably, and to address the technical interaction, the multiannual plan for fisheries exploiting stocks of plaice and sole in the North Sea was launched in 2007 by the European Council (European Union, 2007). The plan consisted of two stages. The first stage aimed to bring the two stocks within safe biological limits, while the second stage should subsequently ensure the exploitation of the stocks on the basis of maximum sustainable yield. The objectives of stage 1 are currently considered being met, and in 2012 the advice by the International Council for the Exploration of the Sea (ICES) was to move towards stage 2 (ICES, 2012b).

The plan (stage 1) prescribes procedures for setting total allowable catches (TACs) each year for plaice and sole, ensuring a sufficient reduction in fishing mortality while limiting the variation in TAC between two consecutive years to $15 \%$. The plan also sets fishing effort limitation for fleets that target and/or discard important amounts of plaice and sole. Fishing effort is to be adjusted annually based on a forecast of the maximum level of fishing effort necessary to take the plaice and sole catch prescribed for the given year. The plan finally lays out how effort and landings should be monitored.

\subsubsection{Applying the evaluation framework}

\section{Step 1: Sustainability assessment}

During the first stage of the plan two objectives were specified for each stock - one for fishing mortality and one for spawning stock biomass. In that respect the plan can be said to apply a neo-classical view of sustainability (Table 3 ). During the second stage of the plan, the single objective is to maintain fishing mortality at its level providing maximum sustainable yield, which can be seen as a step back to a classical view of sustainability.

\section{Step 2: Qualitative assessment of management tactics}

The plan combines TAC reduction with effort control. If implemented with high compliance, these management tactics are qualitatively adequate to meet the goals of the plan, that is, reduce effort (taken as a proxy for fishing mortality) and increase the stocks (Table 3 ). This 
holds with both the core model, model 2 (variable cost subsidies) and model 3 (subsidies and overcapacity). Overcapacity and subsidies are two of the major failings of the Common Fisheries Policy (Commission of the European Communities, 2009). In the particular case of the plaice and sole fisheries in the North Sea, fishing effort has been substantially reduced over the last two decades primarily as a consequence of effort regulation (ICES, 2012b). The effort reduction may have reinforced the link from effort to catch, which was probably weak to start with owing to overcapacity. A second cause for observed effort reduction might be increasing oil prices (ICES, 2012b), suggesting that the link from effort to earnings is active; however, this might not be the case in all member states. For example, fuel subsidies and exemption of various taxes by the French government might have absorbed the fuel price increase for the French fleet participating in this fishery (Mesnil, 2008, Rochet et al., 2012). Thus, in the case of this fishery there is uncertainty about the adequate model structure - all of the core model, model 2 and model 3 might be relevant, perhaps depending on place and time. Nonetheless the evaluation framework highlights that for this fishery it is necessary to understand how national policies on direct and indirect subsidies affect effort, before it is possible to evaluate the ability of the management plan to achieve its objectives.

The uncertainty about which model variant applies has little effect on the conclusions, since reducing catch and effort is predicted to increase stock and decrease effort with all model variants. However, the impact on economic variables is generally not predictable, and more likely to be negative in the case of model 2 . Therefore from a theoretical point of view the success of this plan will depend on the relative magnitude of the parameters determining earnings and profitability - which might vary across member states. In unfavourable economic conditions the plan may not meet its objectives, unless it would be accompanied by incentives and/or economic compensations to help acceptability and compliance by the industry. Currently the European Fisheries Fund (EFF) is providing such a mechanism, allocating public aid to owners of fishing vessels and fishers affected by fishing effort adjustment plans where these form part of recovery or multi-annual management plans (European Union, 2006).

\section{Step 3: Qualitative assessment of complementary measures}

The plaice and sole plan does not include any provision about equitable allocation of losses and benefits of the stocks" recovery at the scale of the entire fishery. Assistance is provided as public aid to fishing effort adjustment and socio-economic compensation for the fishing fleet management under the EFF (Table 3). But, since member states are liable for monitoring and enforcement of both quota and effort reductions, and for individual allocation of EFF, differences in policy and economics among member states may result in nonequitable outcomes for individual fishers. Like many EU long-term management plans, the North Sea plaice and sole multiannual plan constrains annual TAC variations to be below $15 \%$. This stabilizing measure might have resulted in a low initial reduction in $F$, though it did not prevent fishing mortality to be reduced substantially over time (Figure 2). Besides, effort limitation in this plan is closely related to catch limitation: effort variation is to be calculated every year so as to match TAC variation under the current assessment and projection model. So reduction in fishing effort is not really an additional management tactic, but merely part of catch management.

On the positive side, this multi-annual plan is multispecies in essence, since it targets two stocks and addresses a major technical interaction between them. The performance indicators and their reference points are clearly and explicitly set for both stocks. The plan also provides for monitoring, inspection and surveillance of vessels operating in the area (using satellite-based vessel monitoring systems) and their landings (Table 3).

Step 4: Quantitative simulations 
To complement the qualitative analyses, a quantitative bio-economic management strategy evaluation should establish which fleets would bear the costs and which fleets would take the benefits of the stocks" recovery, and the true effect of subsidies on effort changes. Carrying out such simulations is beyond the scope of this manuscript.

\subsubsection{Insights from applying the evaluation framework}

In summary, the outcome of the illustrative qualitative evaluation (steps 1 -3) of the North Sea plaice and sole multi-annual management plan is mixed (Table 3 ). The stated long term objectives of the plan might not be consistent with sustainable exploitation of plaice and sole. In contrast, the management provisions might allow the stated objectives to be reached, but a quantitative evaluation of the economic costs and benefits to the individual fishers is still required to fully assess its acceptability - this would include examining whether costs and benefits are likely to be equitably shared among fishers. Further, from a theoretical point of view the rule limiting annual TAC variations might compromise the plan's success.

Comparing empirical evidence with theoretical predictions, application of the plan seems to have been successful in accelerating the decrease in sole fishing mortality, which was slowly declining since the late 1990s (Figure 2a). In contrast, plaice fishing mortality was already steeply declining and this decline slowed down and even stopped following implementation of the plan, since the target for plaice fishing mortality was met in 2008. Following the decline in fishing mortality, plaice Spawning Stock Biomass (SSB) increased; sole SSB reached a minimum in 2007 and increased thereafter (Figure 2b).

The objectives of the first stage of the plan are now met (ICES, 2012b), and fishing mortality rates are at or very near the MSY reference points, that is, the targets of the second stage of the plan. The question is now, whether the plan is capable to maintain the fishing mortality on the MSY level. This is not obvious in a changing context. Indeed, new trawls with improved catchability and a different selectivity are increasingly used by the fishing fleets (ICES, $2012 \mathrm{~b}$ ). Besides, the upcoming reform of the Common Fisheries Policy includes major changes in the regulations concerning discards, which will probably significantly affect the sole and plaice fishery in the southern North Sea.

\subsection{Roundnose grenadier}

No formal management plan exists for the roundnose grenadier stock to the west of the British Isles, but a number of management tactics and measures have been put into place by the European Commission in the last decade which taken together contain the elements of a management plan (Table 3).

\subsubsection{Background information}

Roundnose grenadier is a low productivity, long-lived (around 60 years) deep-water species (Lorance et al., 2008). The effort directed at deep-water species by French trawlers increased over the period 1989-1994 (Figure 3a). In 1995, provisions to regulate effort were therefore introduced. However, these regulations were not limiting to the fleet. Starting from 2003 , total allowable catch (TAC) and new effort regulations were put in place. In particular, from that date vessels needed a licence with the overall number of licences being fixed to a certain total vessel power level preventing further entry into the fleet. In 2008, the fishing effort of licensed deep-water fishing vessels was capped. Since 2003, the combination of TAC reduction and effort regulation lead to a decrease in fishing effort (Figure 3a). Landings of roundnose grenadier decreased from 2003 due to decreasing quotas (Figure 3b). At the 
same time the price per $\mathrm{kg}$ for roundnose grenadier increased slightly, but far from proportional to the landings decrease (Figure 3c). The fishery has several target species including deep-water sharks which can only sustain low fishing pressures. Therefore from 2010 the quota for targeted fishing of deep-water sharks was set to zero (European Union, 2008), though the species are probably still bycaught. Finally, since 2004, an onboard observer program collects information on discards of target and non-target species.

This roundnose grenadier stock is assessed by the International Council for the Exploration of the Sea using a Bayesian production model (ICES, 2012d). The stock has strongly decreased over the course of its (short) history of exploitation to about $11-22 \%$ of estimated initial stock biomass (Pawlowski and Lorance, 2009). However, in 2011 fishing mortality was estimated to be below $\mathrm{F}_{\mathrm{MSY}}$ and spawning stock biomass above the MSY $\mathrm{B}_{\text {trigger }}$ level (ICES, 2012c).

\subsubsection{Applying the evaluation framework}

\section{Step 1: Sustainability assessment}

This roundnose grenadier stock is managed according to the modern view of sustainability (Table 3). More precisely, ICES has defined a reference point for spawning stock biomass called MSY $B_{\text {trigger }}$ in addition to a limit fishing mortality $F_{M S Y}$ (ICES, 2012a). Within the ICES advice framework, SSB is to be kept above $B_{\text {trigger }}$ and fishing mortality below $F_{M S Y}$ (ICES, 2012a). Some aspects of a post-modern view of sustainability also apply as deep-water shark catches were reduced by setting their TAC for targeted fishing to zero (Table 3 ).

\section{Step 2: Qualitative assessment of management tactics}

Given reinvestment of profit into fishing capacity is prevented by the licencing scheme and fishing power has a cap, in the model describing this fishery the link from profitability to fishing capacity does not exist. Although nominal fish prices increased by $32 \%$ between 1999 and 2008 following a decrease in landings, this only changes the strength of the link from catch to net earnings and not the sign nor the existence of the link. Thus, model 4 provides an adequate description.

Based on qualitative model predictions using model 4, implementing the two stock management tactics effort restrictions and catch reductions (TAC) should increase stock size and decrease effort (Table 3). As for economic variables, the changes of total net earnings and profitability are unpredictable with model 4 . If effort restrictions were the dominant measure, the conditions of an increase would be related to the coefficients $a_{r e}(E-R$ link) and/or $a_{s e}(E-S)$ being large and/or $a_{c e}(E-C)$ being small. To determine whether indeed profitability and net earnings were expected to increase it is necessary to study the variable fishing costs caused by effort deployment as this determines $a_{r e}$. Higher variable costs per unit effort lead to higher net earnings when effort is reduced. The strength of the link between effort and stock $\left(a_{s e}\right)$ is determined by catchability on the stock level. For evaluating the value of the link between effort and catch $\left(a_{c e}\right)$, information on the factors affecting catch per unit effort needs to be considered.

\section{Step 3: Qualitative assessment of complementary measures}

Several empirical criteria for evaluating complementary measures apply to the roundnose grenadier case study (Table 3). First, a large initial reduction in fishing mortality was probably achieved. Since the introduction in 2003 in European waters (2005 for the whole stock area), the TAC of roundnose grenadier was strongly reduced (ICES, 2012d). This lead to a strong decrease in landings after 2003 in accordance with this criterion (Figure 2b). Second, the 
fishery is a mixed-species fishery, hence the criterion that plans should contain multi-species elements applies. Currently quotas are set independently for each of the major species, including a zero TAC for targeting deep-water sharks. The zero TAC for shark could be considered a multispecies measure though not considering the compatibility of the speciesspecific target TACs could be interpreted as violating the criterion. Third, performance indicators are clearly defined and fourth monitoring of bycatch and discards is in place, and consistent stock monitoring is achieved by carrying out regular (biannual) stock assessments by the ICES working group WGDEEP. Thus the monitoring program criterion is met.

\section{Step 4: Quantitative simulations}

Application of steps 1-3 of the framework helped to identify essential model components as well as issues requiring quantitative simulations. In terms of model structure, a bio-economic simulation model is needed. Also, deep-water shark bycatch considerations need to be taken into account. This is probably most effectively achieved using a model with some spatial structure. Further, quantitative simulations should focus on determining the fishing conditions under which variable fishing costs per unit effort are large - this would allow to resolve the ambiguity in model predictions. Finally, the temporal resolution of the simulation model needs to be fine enough to capture the effects of roundnose grenadier sales prices, and subsequently net earnings, depending on quantities landed (Figure 2b).

\subsubsection{Insights from applying the evaluation framework}

In summary, applying our evaluation framework to the roundnose grenadier fishery leads to the conclusion that the current management objectives and measures are compatible with sustainable long term exploitation and recovery of the stock biomass (Table 3 ). The increasing stock size without compromising economic profitability of the remaining participants in the fishery might be achievable under certain economic conditions. Unfortunately no specific economic information is available for the vessels exploiting deepwater species, which makes it difficult to validate this prediction.

Comparing the results of the theoretical evaluation with the observed changes, the management measures put in place have stopped further stock decrease as predicted, though signs of notable stock biomass recovery are still weak (Figure $3 b$ ).

\section{Discussion}

We proposed a framework for evaluating fisheries management plans which combines an assessment of the sustainability of the stated objectives with the use of qualitative results of a bio-economic model to test proposed management tactics, and, when appropriate, suites of management measures, in a general manner, and application of empirical criteria for the other dimensions of the plan. Based on the insights gained, the last step consists of quantitative simulations for specific questions. Although the economic consequences of the multi-annual plan for fisheries exploiting plaice and sole in the North Sea were not predictable, we inferred a reasonable adequacy of the plan to meet its objectives, owing to an appropriate combination of management tactics and complementary measures. The application to roundnose grenadier showed how to use the framework in a case with no formal management plan, but nevertheless a number of formalized management tactics and measures in a mixed-species fishery. The main advantage of the framework is the simplicity and rapidity of the first three steps, with time consuming model parameterisation and simulation runs restricted to one or a small number of specific models and issues. For example, in the roundnose grenadier example, the simulations that would be most 
informative about the potential efectivensss of the management plan would be related to how fishery costs vary with CPUE, and complex simulations of roundnose grenadier life history and ecology would do little to reduce uncertainty about the potential success of the management plan.

Obtaining qualitative model predictions for other model formulations than those explored here would only take a few minutes. For example, Bunnefeld et al. (2011) proposed to extend the use of MSE, which are already popular in fisheries, to the wider context of conservation management evaluation. But as stressed by those authors, this can only be done if the harvester behaviour is included in the model, something particularly difficult to translate into formal equations and to parameterize (Fulton 2011). Human behaviours may be more easily translated into qualitative models.

The qualitative analysis of management tactics revealed that several tactics need to be combined for increasing stock size without decreasing the economic performance of the fishery. Of course, effort or capacity reduction schemes often result in some participants being displaced completely from a fishery. In this case only the economic performance of the remaining fishers is unaltered or even improved, but the displaced fishers suffer a complete loss of economic returns until they are able to find employment outside the fishery being considered. Rosenberg and Morgensen (2005) also concluded that catch reductions should be combined with other tactics such as closed areas, effort control or capacity reduction. While those authors thought the combination of tactics would provide an insurance against uncertainty, we showed that this is inherent in fishery dynamics even in a deterministic view. However, we concur that uncertainty and variability compromise the efficiency of any particular management tactic and strengthen the need for a combination of tactics.

Selecting appropriate management tactics is only part of the story. The life history of the species and the environment also play an important role, in particular for the time it might take for a stock to rebuild (Powers, 2003, Wakeford et al., 2009). Clearly, species with slow life histories such as roundnose grenadier cannot be expected to react at the same rate as the less long lived plaice or sole. Moreover, highly depleted stocks often have low productivity (Rice et al., 2003). Our bio-economic model still applies in situations where the stock-productivity relationship is depressed, with depensation resulting in reduced per capita productivity (which is the biological rationale for biomass limit reference points to begin with). This is unlike quantitative models parameterized with data from periods of larger, more productive stocks. However, the time to actually observe positive effects of combinations of management measures needed for stock recovery will be extended. Thus, the delay in expected feedback from depleted stocks gives additional value to a qualitative model step that can screen out management approaches likely to fail to promote stock recovery.

Though the assessment of management tactics and other management measures were carried out in two separate steps, certain issues are linked. The mortality reduction criterion states that for rebuilding plans the reduction of fishing mortality should be initially substantial rather than gradually incremental. This is nevertheless consistent with the qualitative bioeconomic model analysis because it functionally ensures that the behaviour of fish and fishers reflected by the effort-catch link does not adapt at the same rate that effort is reduced. The initiation of recovery plans before depensation has set in is equivalent to the stock-catch link maintaining its characteristic strength. The multi-species criterion recommends taking impacts on other species into account. In terms of the bio-economic model this corresponds to maintaining the stock - catch link, i.e. preventing alterations by other fisheries.

The framework might be especially useful in data-limited situations. Evaluation and management of stocks with limited amounts of data is going to be increasingly required under the ecosystem approach to fisheries management banner. Bycatch species with limited, poor quality or lacking landings data will still need to be addressed in management, 
especially if they are considered vulnerable or endangered by fishing activities or for some other reason.

For evaluating the sustainability of objectives in data-limited fisheries there will be at best relative indicators of trend in the status of the harvested species and the economic benefits derived from the fishery, e.g. Australian tier system (Smith et al., 2008). In some cases the best information available may be limited to traditional knowledge of fishers and their perception of the present fishing conditions relative to the past; agreement between fishers' perceptions and scientific survey data has been demonstrated for the Eastern English channel (Rochet et al., 2008). In other cases there may be trends in commercial or survey CPUE, but no ability to link those trends to actual biomass or fishing mortality measures (Cotter et al., 2009). Absolute measures of stock biomass, fishing mortality etc. are not likely to be available. Even with limited relative information, stocks might be identified as being in need of rebuilding, and managers may attempt to promote rebuilding using whatever tools they think they can apply effectively - usually input or output control and/or spatial-temporal measures. The objective to improve stock status can be tracked through the same information sources used to conclude rebuilding was necessary. There may be little basis to chose a specific reference value on the relative indicators (or traditional knowledge) to represent the rebuilt condition for the stock. However the management objective for the medium term can be as simple as "improvement" reflected in whatever indicator is available. Periodic reviews of the indicator(s), particularly patterns in the rate of change of the indicators and their status relative to historical values, can provide some feedback on whether further growth in the stock is likely under an appropriate management regime, or if the management objective should change from "improvement " to " relative stability " in the indicators, reflecting a sustainable use of the rebuilt resource.

The reliance on rate of change in relative indicators of stock status or ratio of current to past values for an indicator as the basis to evaluate both success of a management plan to promote recovery and opportunity for yet further stock recovery makes it particularly important to have a framework which evaluates if the management plan itself has a fair chance of allowing rebuilding, without requiring the model to capture analytically all important aspects of the stocks" population dynamics, ecosystem interactions, fishery behaviour and economics. A general framework is necessary to determine whether failure of the indicators to show improvement of the stock over time occurs because the stock actually is no longer depleted and does not need to rebuild further, or because the measures are simply the wrong ones for the fishery, and other suites of management measures could promote further rebuilding.

Our evaluation framework only considers objectives and tactics to achieve them in a singlespecies context. Given both the commonness of mixed fisheries and the widespread adoption of an ecosystem approach to fisheries, this is too narrow a framework for full consideration of the sustainability of a fishery. However, our plaice - sole example shows that the evaluation framework can be applied readily in mixed fishery contexts. Indeed the expansion of the qualitative bio-economic model to include important mixed fishery linkages is relatively straightforward, whereas expanding quantitative bio-economic models to include mixed fishery interactions becomes difficult quickly. On the other hand the larger ecosystem considerations can more readily be accommodated in the objective-setting part of the plan. This seems to be emerging as a best practice for moving fisheries into an ecosystem context in any case: when setting management objectives for the state of an exploited stock account should be taken of the impacts of ecosystem drivers on stock dynamics and of the role of the harvested species in the food web (Gislason et al., 2000). With objectives set in this broader ecosystem context, measures should move the stock to - or keep the stock in - a state that is not just productive for the fishery, but also robust to likely environmental forcers and able to play its role in ecosystem processes. Only in special circumstances would management tactics be directed at a predator or prey or specific habitat feature, and even in those cases 
success of the tactics would still be evaluated by changes in the status of the harvested stock itself. As explained above, the post-modern view for evaluating sustainability of fisheries management objectives includes these ecosystem considerations when appropriate.

\section{Acknowledgements}

The study was carried out with financial support from the Commission of the European Communities under the DEEPFISHMAN project (grant agreement no. 227390). We thank Pascal Lorance for providing the information for the roundnose grenadier case study and useful comments on the manuscript. We also thank Sarah Kraak and André Punt for their constructive reviews of an earlier version of this manuscript. We are grateful to Lionel Pawlowski for providing the roundnose grenadier stock assessment biomass values.

\section{References}

Bastardie, F., Vinther, M., Nielsen, R.J., Ulrich, C., Storr Paulsen (2010) Stock-based vs. fleet-based evaluation of the multi-annual management plan for the cod stocks in the Baltic Sea. Fisheries Research 101, 188-202.

Bence, J.R., Dorn, M.W., Irwin, B.J., Punt, A.E. (2008) Recent advances in the evaluation and implementation of harvest policies. Fisheries Research 94, 207-209.

Brodziak, J.K.T., Cadrin, S.X., Legault, C.M., Murawski, S.A. (2008) Goals and strategies for rebuilding New England groundfish stocks. Fisheries Research 94, 355-366.

Bunnefeld, N., Hoshino, E., Milner-Gulland, E.J. (2011) Management strategy evaluation: a powerful tool for conservation? TRENDS in Ecology and Evolution 26, 441-447.

Caddy, J.F., Mahon, R. (1995) Reference points for fisheries management. FAO Fisheries Technical Paper No. 347, 83pp.

Christensen, V. (2010) MEY = MSY. Fish and Fisheries 11, 105-110.

Commission of the European Communities (2009) Green Paper. Reform of the Common Fisheries Policy. COM(2009) 163 final. 27pp.

Cotter J., Petitgas P., Abella A., Apostolaki P., Mesnil B., Politou C.-Y., Rivoirard J., et al. (2009) Towards an ecosystem approach to fisheries management (EAFM) when trawl surveys provide the main source of information. Aquatic Living Resources 22, 243254.

Dambacher, J.M., Gaughan, D.J., Rochet, M.-J., Rossignol, P.A., Trenkel, V.M. (2009) Qualitative modelling and indicators of exploited ecosystems. Fish and Fisheries 10, 305-322.

Dambacher, J.M., Li, H.W., Rossignol, P.A. (2002) Relevance of community structure in assessing indeterminacy of ecological predictions. Ecology 83, 1372-1385.

Department of Agriculture, Fisheries and Forestry, (2007) Commonwealth fisheries harvest strategy policy and guidelines. Available at: http:/www.daff.gov.au/fisheries/domestic/harvest_strategy_policy (accessed 26 July 2013).

Dwyer, R.L., K.T., P. (1983) An experimental examination of ecosystem linearization. American Naturalist 121, 305-323.

Ellner, S.P., Gross, L.J. (1982) Population dynamics and local linearization. Ecology 63, 1989-1990.

European Union (2002) Council Regulation (EC) No 2371/2002 of 20 December 2002 on the conservation and sustainable exploitation of fisheries resources under the Common Fisheries Policy. Official Journal of the European Union L 358, 59-80. 
European Union (2006) Council Regulation (EC) No 1198/2006 of 27 July 2006 on the European Fisheries Fund. Official Journal of the European Union L 223, 1-44.

European Union (2007) Council regulation (EC) No 676/2007 of 11 June 2007 establishing a multi-annual plan for fisheries exploiting stocks of plaice and sole in the North Sea. Official Journal of the European Union L157, 1-6.

European Union (2008) Council Regulation (EC) No 1359/2008 of 28 November 2008 fixing for 2009 and 2010 the fishing opportunities for Community fishing vessels for certain deep-sea fish stocks. Official Journal of the European Union L 352, 1-10.

Gislason, H., Sinclair, M., Sainsbury, K., O'Boyle, R. (2000) Symposium overview : incorporating ecosystem objectives within fisheries management. ICES Journal of Marine Sciences 57, 468-475.

Hilborn, R., Walters, C.J. (1992) Quantitative Fisheries Stock Assessment: Choice, Dynamics and Uncertainty. Chapman and Hall, New York.

ICES (2012a) Advice 2012, Book 1. Available at: http://www.ices.dk/publications/library (accessed 26 July 2013).

ICES (2012b) Advice 2012, Book 6. Available at: http://www.ices.dk/publications/library (accessed 26 July 2013).

ICES (2012c) Advice 2012, Book 9. Available at: http://www.ices.dk/publications/library (accessed 26 July 2013).

ICES (2012d) Report of the working group on biology and assessment of deep-sea fisheries resources (WGDEEP). ICES CM 2012/ACOM: 17, 942pp.

Kraak, S.B.M., Reid, D.G., Gerritsen, H.D., et al. (2012) 21st century fisheries management: a spatio-temporally explicit tariff-based approach combining multiple drivers and incentivising responsible fishing. ICES Journal of Marine Science 69, 590-601.

Link, J.S. (2010) Ecosystem-based Fisheries Management: confronting Tradeoffs. Cambridge University Press, Cambridge.

Lorance, P., Large, P.A., Bergstad, O.A., Gordon, J.D.M. (2008) Grenadiers of the NE Atlantic - distribution, biology, fisheries and their impacts, and developments in stock assessment and management. In: Grenadiers of the world oceans: biology, stock assessment and fisheries. Vol. 63. (Eds. A. Orlov, T. Iwamoto), American Fisheries Society Symposium, Bethesda, MS, USA, pp. 365-397.

Mesnil, B. (2008) Public-aided crises in the French fishing sector. Ocean \& Coastal Management 51, 689-700.

Murawski, S.A. (2010) Rebuilding depleted fish stocks: the good, the bad and, mostly, the ugly. ICES Journal of Marine Science 67, 1830-1840.

Nakajima, H. (1992) Sensitivity and stability of flow networks. Ecological Modelling 62, 123133.

Pawlowski, L. and Lorance, P. (2009) Effect of discards on roundnose grenadier stock assessment in the Northeast Atlantic. Aquatic Living Resources 22, 573-582.

Powers, J.E. (2003) Principles and realities for successful fish stock recovery - a review of some successes and failures. ICES CM 2003/U: 12, 14pp.

Puccia, C.J. and Levins, R. (1985) Qualitative Modeling of complex Systems: an Introduction to Loop Analysis and Time averaging. Harvard University Press, Cambridge.

Punt, A.E. and Donovan, G.P. (2007) Developing management procedures that are robust to uncertainty: lessons from the International Whaling Commission. ICES Journal of Marine Science 64, 603-612.

Rice, J.C., Shelton, P.A., Rivard, D., Chouinard, G.A., Fréchet, A. (2003) Recovering Canadian Atlantic cod stocks: the shape of things to come? ICES CM 2003/U:06, 23pp.

Rochet M.-J., Prigent M., Bertrand J.A., Carpentier A., Coppin F., Delpech J.-P., Fontenelle G., et al. (2008) Ecosystem trends: evidence for agreement between fishers" perceptions and scientific information. ICES Journal of Marine Science 65, 10571068. 
Rochet, M.J., Collie, J.S., Trenkel, V.M. (2013) How do fishing and environmental effects propagate among and within functional groups? Bulletin of Marine Science 89, 285315.

Rochet, M.J., Daurès, F., Trenkel, V.M. (2012) Capacity management, not stock status or economics, drives fleet dynamics in the Bay of Biscay ecosystem on a decadal time scale. Canadian Journal of Fisheries and Aquatic Science 69, 695-710.

Rochet, M.J., Rice, J.C. (2009) Simulation-based management strategy evaluation: ignorance disguised as mathematics? ICES Journal of Marine Science 66, 754-762.

Rosenberg, A.A., Morgensen, C.B. How can rebuilding plans achieve the objective of recovery of overfished stocks? ICES CM 2005/W: 01, 29pp.

Rosenberg, A.A., Swasey, J.H., Bowman, M. (2006) Rebuilding US fisheries: progress and problems. Frontiers in Ecology and the Environment 4, 303-308.

Sainsbury, K.J., Punt, A.E., Smith, A.D.M. (2000) Design of operational management strategies for achieving fishery ecosystem objectives. ICES Journal of Marine Science 57, 731-741.

Smith, A.D.M., Sainsbury, K.J., Stevens, R.A. (1999) Implementing effective fisheriesmanagement systems - management strategy evaluation and the Australian partnership approach. ICES Journal of Marine Science 56, 967-979.

Smith A.D.M., Smith D.C., Tuck G.N., Klaer N., Punt A.E., Knuckey I., Prince J., et al. (2008) Experience in implementing harvest strategies in Australia's south-eastern fisheries. Fisheries Research 94, 373-379.

Wakeford, R.C., Agnew, D.J., Mees, C.C. (2009) Review of institutional arrangements and evaluation of factors associated with successful stock recovery plans. Reviews in Fisheries Science 17, 190-222. 
Table 1. Outline of framework for evaluating management plans.

\begin{tabular}{|c|c|c|}
\hline Step & Question asked & Method \\
\hline 1 & $\begin{array}{l}\text { Are the objectives of the } \\
\text { management plan sustainable? }\end{array}$ & Scrutiny of objectives and reference points \\
\hline 2 & $\begin{array}{l}\text { Are the proposed management } \\
\text { tactics likely to achieve the } \\
\text { objectives of the management } \\
\text { plan for the target stock? }\end{array}$ & $\begin{array}{l}\text { Qualitative bio-economic model analysis } \\
\text { 1. Adapt generic model to specific } \\
\text { fishery / situation } \\
\text { 2. Translate envisaged management } \\
\text { tactics into "press perturbations" } \\
\text { 3. Qualitatively predict the expected } \\
\text { outcomes } \\
\text { 4. Examine under which conditions } \\
\text { these outcomes meet the plan } \\
\text { objectives }\end{array}$ \\
\hline 3 & $\begin{array}{l}\text { Are the proposed socio- } \\
\text { economic, ecosystem and } \\
\text { monitoring measures likely to } \\
\text { enhance the success of the } \\
\text { management plan? }\end{array}$ & $\begin{array}{l}\text { Comparison of proposed complementary } \\
\text { measures with criteria derived from available } \\
\text { evidence of success. }\end{array}$ \\
\hline 4 & $\begin{array}{l}\text { Which harvest control rules, } \\
\text { quota or effort levels, etc. might } \\
\text { perform best (minimise transition } \\
\text { effects, the time to reach the } \\
\text { objectives,...)? }\end{array}$ & $\begin{array}{l}\text { Quantitative simulations with models } \\
\text { representing relevant subsets of the system. }\end{array}$ \\
\hline
\end{tabular}


Table 2. Predicted directions of change of ecological and fisheries state variables in core bioeconomic model (Figure 1) when applying eight stock rebuilding management tactics using press perturbation analysis: - decrease, + increase, 0 no effect, ? direction of effect uncertain (as many positive as negative impacts). Results in brackets are ambiguous. For example, $(+)$ means that the state variable will increase in most instances, but might decrease if the links forming negative loops are stronger than the links contributing to positive loops; these conditions can be written explicitly (see text).

\begin{tabular}{|c|c|c|c|c|c|c|}
\hline \multirow[b]{3}{*}{$\begin{array}{l}\text { Management } \\
\text { tactic }\end{array}$} & \multicolumn{6}{|c|}{ Predicted direction of change of state variable } \\
\hline & Stock $S$ & Effort $E$ & $\begin{array}{c}\text { Net } \\
\text { earnings } R\end{array}$ & Profitability $P$ & Capacity $K$ & Catch $C$ \\
\hline & & & & & & \\
\hline $\begin{array}{l}\text { Decrease in quota } \\
\text { (C) }\end{array}$ & $+{ }^{m}$ & $-{ }^{m}$ & - & $-{ }^{m}$ & $-{ }^{m}$ & - \\
\hline Decrease effort $(E)$ & + & - & $(+)^{m}$ & $(+)^{m}$ & $(+)^{m}$ & $?^{\mathrm{m}}$ \\
\hline $\begin{array}{l}\text { Increase tax } \\
(\text { decrease } R)\end{array}$ & $+{ }^{m}$ & $-{ }^{m}$ & - & $-{ }^{m}$ & $-{ }^{m}$ & $?^{\mathrm{m}}$ \\
\hline $\begin{array}{l}\text { Decrease capacity } \\
(K)\end{array}$ & + & - & $(+)^{m}$ & $(+)^{m}$ & - & $?^{\mathrm{m}}$ \\
\hline Decrease $E \& K$ & + & - & $?^{\mathrm{m}}$ & $?^{\mathrm{m}}$ & $?^{\mathrm{m}}$ & $?^{\mathrm{m}}$ \\
\hline Decrease $C \& E$ & + & - & $?^{\mathrm{m}}$ & $?^{m}$ & $?^{\mathrm{m}}$ & $?^{\mathrm{m}}$ \\
\hline Decrease $C \& K$ & + & - & $(-)^{m}$ & $(+)^{m}$ & - & $(-)^{m}$ \\
\hline Decrease $C \& R$ & $+{ }^{m}$ & $-{ }^{m}$ & - & $-{ }^{m}$ & $-{ }^{m}$ & $(-)^{m}$ \\
\hline
\end{tabular}


Table 3. Elements of management plans for case studies and results from application of evaluation framework (in italics).

\begin{tabular}{|c|c|c|}
\hline Plan component & Plaice and sole & Roundnose grenadier \\
\hline Stock objectives & $\begin{array}{l}\text { Stage 1: } \mathrm{B}_{\mathrm{PA}}+\mathrm{F}_{\mathrm{MSY}} \\
\text { neo-classical sustainability } \\
\text { Stage } 2 \text { : } \mathrm{F}_{\mathrm{MSY}} \\
\text { classical sustainability }\end{array}$ & $\begin{array}{l}\text { MSY framework } \\
\text { post-modern sustainability }\end{array}$ \\
\hline Management tactics & $\begin{array}{l}\text { TAC, effort limitation } \\
\text { Predictions (core model, } \\
\text { models 2, } 3 \text { - catch \& effort } \\
\text { reduction): stock size } \\
\text { increases, effort decreases, } \\
\text { changes in net earnings and } \\
\text { profitability are unpredictable or } \\
\text { more likely decreasing }\end{array}$ & $\begin{array}{l}\text { Vessel licence scheme, vessel } \\
\text { power and effort cap, TAC } \\
\text { Predictions (model } 4 \text { - catch \& } \\
\text { effort reduction): stock size } \\
\text { increases, effort decreases, and } \\
\text { net earnings and profitability are } \\
\text { unpredictable }\end{array}$ \\
\hline $\begin{array}{l}\text { Other management } \\
\text { measures }\end{array}$ & $\begin{array}{l}\text { Compensation by EFF, multi- } \\
\text { species plan, monitoring of } \\
\text { effort and landings, regular } \\
\text { stock assessment } \\
\text { Industry support, multi-species } \\
\text { elements, performance } \\
\text { indicators, monitoring program }\end{array}$ & $\begin{array}{l}\text { Large reduction in TAC, TAC=0 for } \\
\text { bycaught sharks, closed areas to } \\
\text { protect VMEs (deep-water corals), } \\
\text { discards monitoring, regular stock } \\
\text { assessment } \\
\text { Mortality reduction, multi-species } \\
\text { elements, performance indicators, } \\
\text { monitoring program }\end{array}$ \\
\hline
\end{tabular}




\section{Figures}

Figure 1. Core bio-economic model for the qualitative prediction of consequences of management tactics. In the model variants the crossed out links are missing. Model 1: external income; model 2: subsidies; model 3: subsidies \& overcapacity; model 4: capacity cap. Bubbles indicate state variables, with arrow-ended links for positive effects and circleended links for negative effects on the receiving variable. All variables are self-regulated, which is indicated by negative self effects (circle-ended links ending in the state variable itself). The direct impact of management measures is indicated in grey.

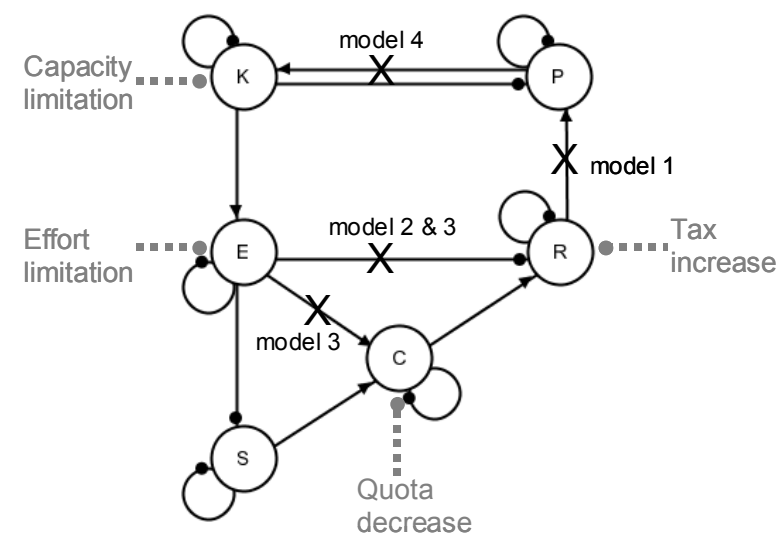

S stock

C catch

$R$ net earnings

P profitability

$\mathrm{K}$ fishing capacity

$E$ effort 
Figure 2. (a) Fishing mortality at ages 2 to 6, and (b) Spawning Stock Biomass for sole and plaice in the North Sea, 1957-2011 (redrawn from ICES 2012a). Dotted lines: MSY reference points (objectives of the multi-annual plan for fisheries exploiting stocks of plaice and sole in the North Sea). Vertical bold gray line: 2007, entry into force of the management plan.

(a)

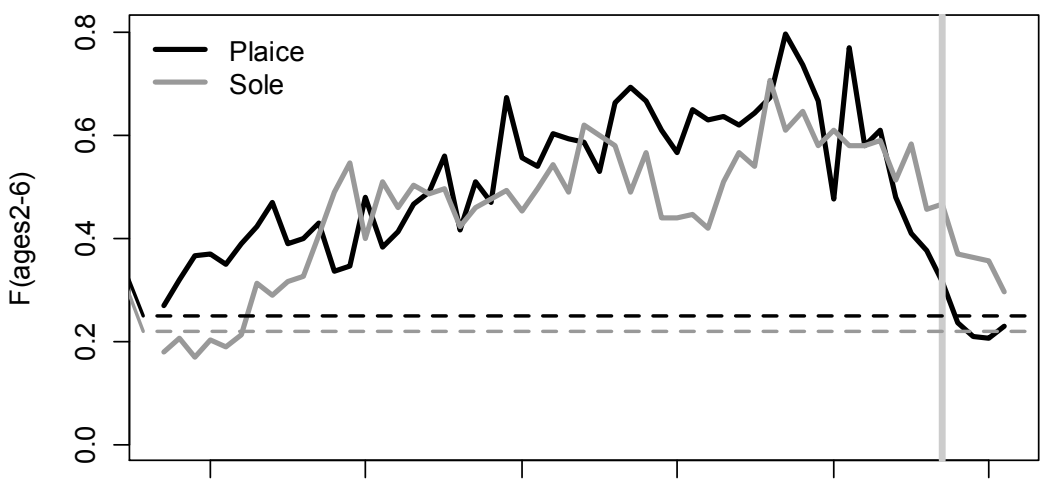

(b)

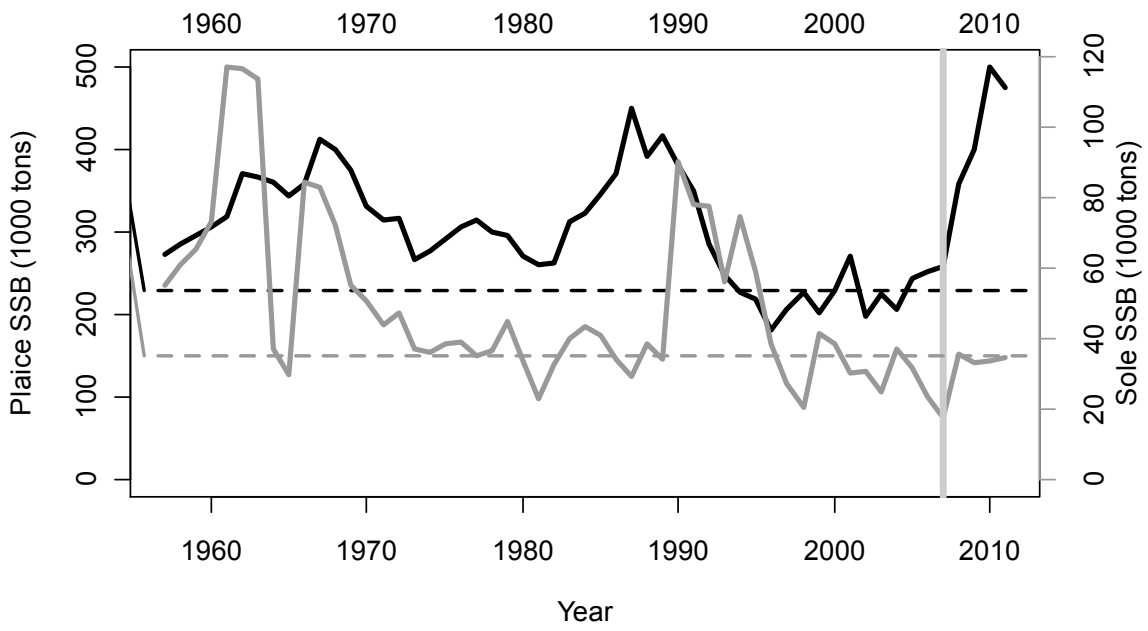


Figure 3. (a) French deep-water bottom trawl fleet size, power and fishing days; (b) International landings for roundnose grenadier (grey bars) and stock biomass estimates from Bayesian production model (continuous line; redrawn from (ICES, 2012c)) for ICES Divisions $\mathrm{Vb}, \mathrm{VI}, \mathrm{VII}$, and XIIb; horizontal line MSY $\mathrm{B}_{\text {trigger }}$ reference level. (c) Average annual French roundnose grenadier ex-vessel price as a function of landings.
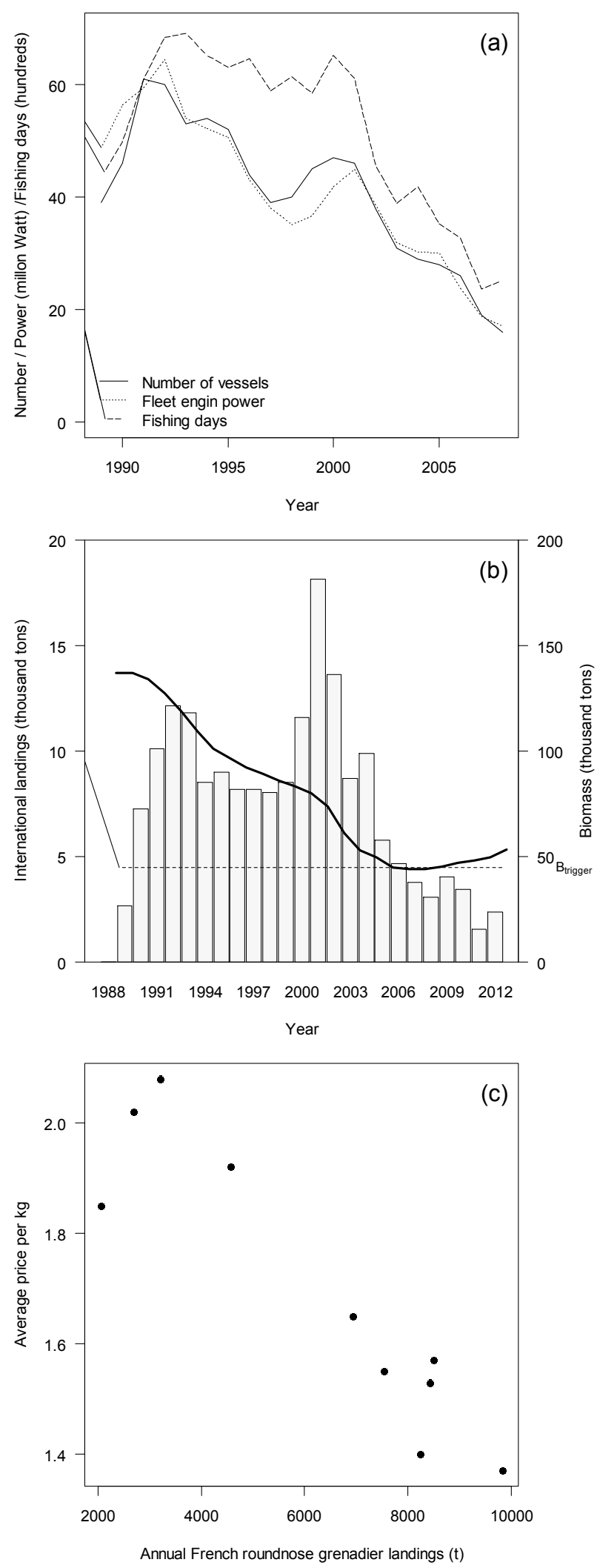


\section{Electronic supplementary material for A framework for evaluating management plans comprehensively}

Table S1. Predicted directions of change of ecological and fisheries state variables when applying eight stock rebuilding management tactics using press perturbation analysis to the core model and four model variants:

Signs: - decrease, + increase, 0 no effect, ? direction of effect uncertain (as many positive as negative impacts). Results in brackets are ambiguous.

Model variants: core (M), external income (M1), variable cost subsidies (M2), subsidies \& overcapacity (M3) and capacity cap (M4), see main text.

\begin{tabular}{|c|c|c|c|c|c|c|}
\hline & & & edicted direction of & Inge of state variab & & \\
\hline & Stock $S$ & Effort $E$ & Net earnings $R$ & Profitability $P$ & Capacity $K$ & Catch $C$ \\
\hline $\begin{array}{l}\text { Management } \\
\text { tactic }\end{array}$ & & & & & & \\
\hline Decrease in quota & $+\mathrm{M}, \mathrm{M} 2, \mathrm{M} 3$ & - M, M2, M3 & - & $-\mathrm{M}, \mathrm{M} 2, \mathrm{M} 3, \mathrm{M} 4$ & $-\mathrm{M}, \mathrm{M} 2, \mathrm{M} 3$ & - \\
\hline (C) & $0 \mathrm{M} 1, \mathrm{M} 4$ & $0 \mathrm{M} 1, \mathrm{M} 4$ & all & $0 \mathrm{M} 1$ & 0 M1, M4 & all \\
\hline Decrease effort & + & - & $(+) \mathrm{M}, \mathrm{M} 1, \mathrm{M} 2$ & $(+) \mathrm{M}, \mathrm{M} 2$ & $(+) \mathrm{M}, \mathrm{M} 1$ & ? M, M1, M2, \\
\hline & all & all & $+\mathrm{M} 3$ & $0 \mathrm{M} 1$ & $0 \mathrm{M} 1, \mathrm{M} 4$ & M4 \\
\hline & & & ? M4 & $+\mathrm{M} 3$ & $+\mathrm{M} 3$ & $-\mathrm{M} 3$ \\
\hline & & & & ? M4 & & \\
\hline Increase tax & $+\mathrm{M}, \mathrm{M} 2, \mathrm{M} 3$ & -:M, M2, M3 & - & $-\mathrm{M}, \mathrm{M} 2-4$ & $-\mathrm{M}, \mathrm{M} 2, \mathrm{M} 3$ & ? M, M2 \\
\hline (decrease $R$ ) & 0 M1, M4 & 0 M1, M4 & all & 0 M1 & 0 M1, M4 & 0 M1, M4 \\
\hline Decrease capacity & + & - & (+) M, M1 & $(+) \mathrm{M}, \mathrm{M} 2, \mathrm{M} 4$ & - all & ? M, M1, M2, \\
\hline$(K)$ & all & all & $\begin{array}{l}\text { ? M2, M4 } \\
+ \text { M3 }\end{array}$ & + M1, M3 & & $\begin{array}{c}\mathrm{M} 4 \\
+\mathrm{M} 3\end{array}$ \\
\hline Decrease $E \& K$ & + & - & $? \mathrm{M}, \mathrm{M} 1, \mathrm{M} 2, \mathrm{M} 4$ & $? \mathrm{M}, \mathrm{M} 1, \mathrm{M} 2, \mathrm{M} 4$ & ? M, M3 & ? M, M1, M2, \\
\hline & all & all & $+\mathrm{M} 3$ & $+\mathrm{M} 3$ & - M1, M4 & M4 \\
\hline & & & & & (-) M2 & $+\mathrm{M} 3$ \\
\hline Decrease $C \& E$ & + & - & $? \mathrm{M}, \mathrm{M} 1, \mathrm{M} 2, \mathrm{M} 4$ & ? & ? & ? M, M3, M4 \\
\hline & all & all & (-) M2 & $0 \mathrm{M} 1$ & 0 M1 \& M4 & (-) M1, M2 \\
\hline & & & & (-) M2 & $(-) \mathrm{M} 2$ & \\
\hline Decrease $C \& K$ & + & - & (-) M, M1-3 & $(+) \mathrm{M}, \mathrm{M} 3$ & - & (-) M, M1-3 \\
\hline & all & all & ? M4 & $+\mathrm{M} 1$ & & ? M4 \\
\hline & & & & ? M2, M4 & & \\
\hline Decrease $C \& R$ & $+\mathrm{M}, \mathrm{M} 2, \mathrm{M} 3$ & - M, M2, M3 & - & $-\mathrm{M}, \mathrm{M} 2-4$ & $-\mathrm{M}, \mathrm{M} 2, \mathrm{M} 3$ & $(-) \mathrm{M}, \mathrm{M} 2, \mathrm{M} 3$ \\
\hline & 0 M1, M4 & 0 M1, M4 & all & $0 \mathrm{M} 1$ & 0 M1, M4 & - M1, M4 \\
\hline
\end{tabular}

